Recibido: septiembre de 2016

Aprobado: octubre de 2016

DOI:

http://dx.doi.org/10.15332/rev.m.v/3i0.1997

\section{LAS EXPOSICIONES UNIVERSALES DENTRO DE LA ESFERA DE LOS GRANDES EVENTOS*}

\author{
Carlos Humberto Gómez Arciniegas** - Universidad Santo Tomás, Colombia
}

Pabellón de México en Expo Milán 2015

Fuente: Carlos Humberto Gómez Arciniegas, 2015.

Artículo de reflexión.

Arquitecto por la Universidad Santo Tomás Bucaramanga, Colombia; especialista en Planificación del Territorio para el Desarrollo por el Politécnico di Milano, Italia - Universite de Paris I, Pantheon-Sorbonne, París, Francia MSc. en Relaciones Internacionales y Estudios Estratégicos con énfasis en Políticas de Desarrollo de Lancaster University, Inglaterra y Ph.D. en Planificación Urbana, Territorial y Ambiental - Politécnico di Milano, Italia Docente investigador, líder de la línea de Investigación en Planificación y Gestión del Territorio adscrita al grupo de Investigaciones de la Facultad de Arquitectura de la Universidad Santo Tomás Bucaramanga.Correo electrónico: carlos.gomez@ustabuca.edu.co

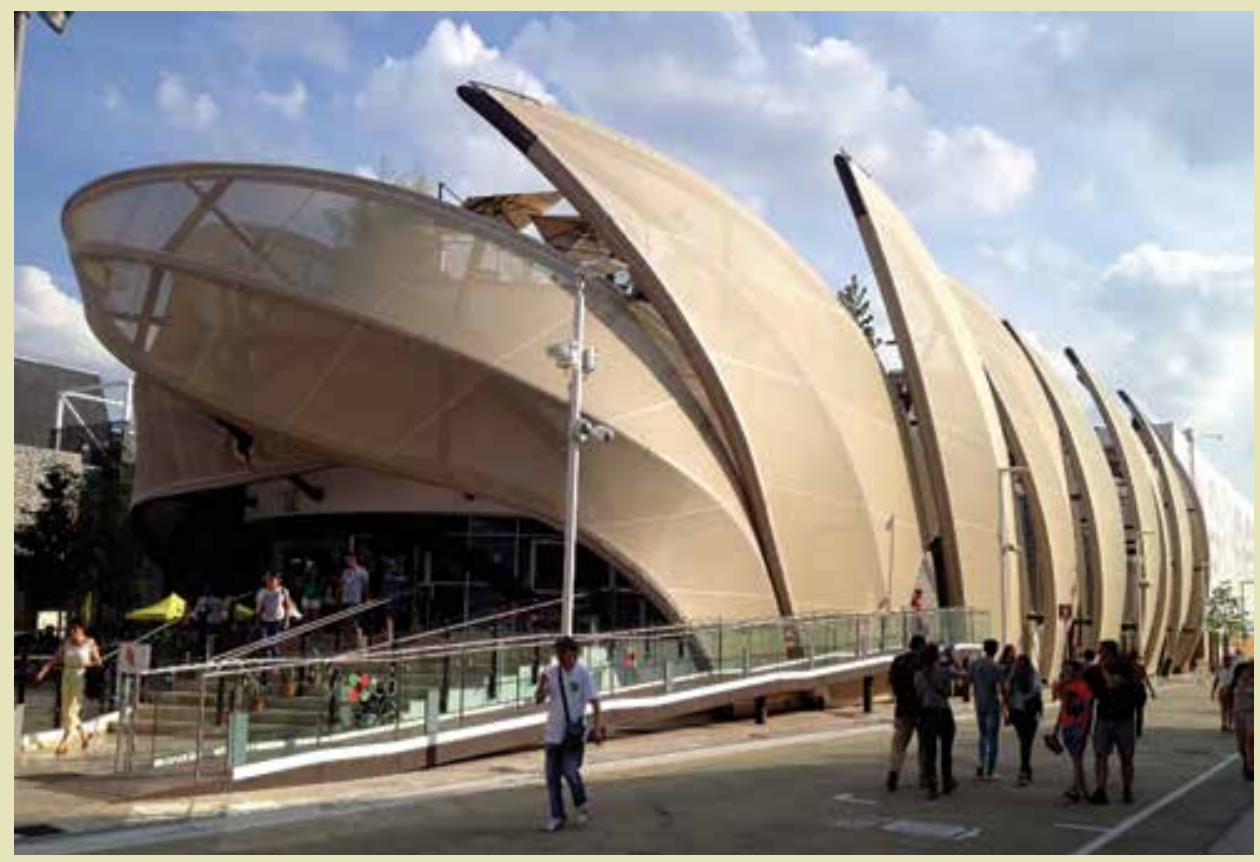

\section{RESUMEN}

Los grandes eventos son iniciativas culturales, comerciales o deportivas de duración limitada y de alto perfil. A pesar de su vigencia, no son exclusivos de la era moderna, pues son un fenómeno muy antiguo: los primeros Juegos Olímpicos tuvieron lugar en 776 a.C. y el primer Jubileo Católico se celebró en I 300 d.C. Cada evento tiene un período de vida relativamente corto, pero las implicaciones relacionadas que conlleva pueden tener efectos que van más allá de sus días de actividad, tanto en la fase de preparación como en las consecuencias que acarrea a largo plazo. Sin ánimo de ser exhaustivo, el artículo busca informar al lector sobre la naturaleza de las exposiciones internacionales dentro de la esfera de los grandes eventos, los cuales ofrecen amplios canales para el desarrollo de eventuales investigaciones que se asumen más como una ocasión de recualificación y valorización urbana, que como un reto insuperable en la carrera de las ciudades por proyectarse y ser más competitivas. Por tanto, el artículo inicia con una aproximación a los grandes eventos y a sus diferentes connotaciones tipológicas para después concentrarse en las renombradas "Exposiciones Universales" y presentar los principales aspectos relacionados con su evolución en el tiempo, su actual estructura organizativa, los alcances que se imponen según su caracterización, el rol que juegan en los procesos de transformación de las ciudades que las acogen y, en modo sucinto, los retos que su planificación demanda antes y después de su materialización.

\section{PALABRAS CLAVE}

Exposiciones, grandes eventos, intervenciones, gestión, competitividad, universal, internacional. 


\section{THE UNIVERSAL EXPOSITIONS WITHIN THE SPHERE OF MAJOR EVENTS}

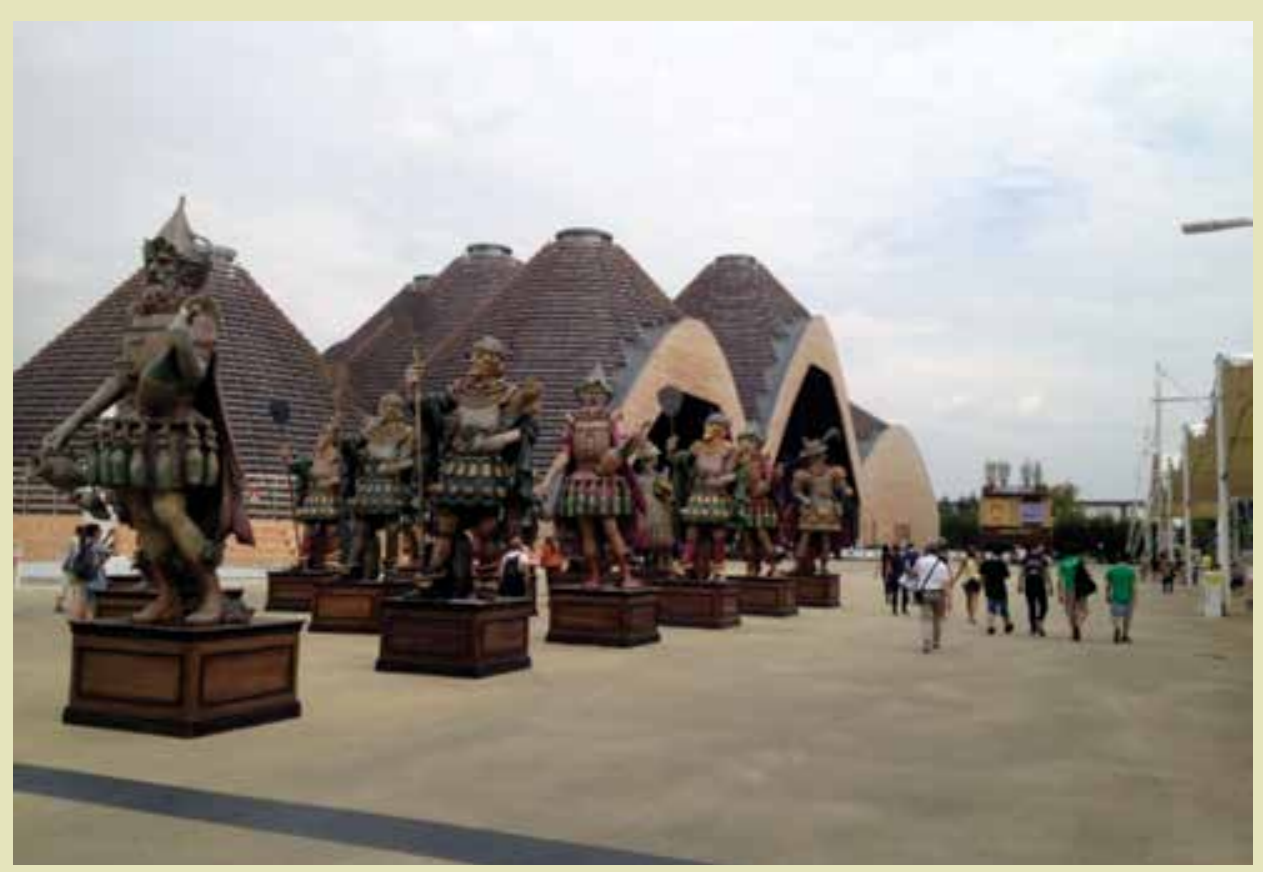

Entrada principal al recinto Expo Milano 2015. Al fondo, el pabellón de la ONU Fuente: Carlos Humberto Gómez Arciniegas, 2015.

\begin{abstract}
Major events are cultural, commercial or sports initiatives of limited duration and high profile. Despite their validity, they are not exclusive to the modern era since they are a very old phenomenon: the first Olympic Games took place in 776 a. C. and the first Catholic Jubilee was celebrated in I 300 AD. Each event has a relatively short life span but the related implications that it entails may have effects that go beyond its days of activity, both in the preparation phase and in the long-term consequences. Without intending to be exhaustive, the article seeks to inform the reader about the nature of International Exhibitions within the sphere of major events, which offer wide channels for the development of possible investigations that should assume them more common an occasion of requalification and valorization urban that an insurmountable challenge in the race of cities to project themselves and be more competitive. Therefore, the article begins with an approach to the Major Events and their different typological connotations. After it, the paper goes on the renowned "Universal Exhibitions" and present the main aspects related to their evolution over time, their current organizational structure, the scope of they impose, according to their characterization, the role they play in the transformation processes of the cities that host them and, in a succinct way, the challenges that their planning demands before and after their materialization.
\end{abstract}

\section{KEYWORDS}

Expositions, major events, interventions, management, competitiveness, universal, international. 


\section{INTRODUCCIÓN}

La ciudad es escenario de constantes cambios debido a múltiples factores, como la aplicación de diversos paradigmas de la modernidad que en muchas ocasiones contradicen sus raíces y su tradición urbana, pero que de una $u$ otra forma buscan acomodo debido a las imposiciones de un mundo cada día más globalizado y competitivo. Actualmente, el desarrollo de la ciudad se sitúa entre dos bifurcaciones al parecer irreconciliables: el modelo globalizado, competitivo y productivo contra el modelo de desarrollo sostenible, basado en la participación ciudadana y en la realidad económica de cada contexto. Si bien estos patrones tienen ya varios años generando reflexiones y literatura a su alrededor, su influencia conjunta sobre la ciudad y el resultado que su confrontación reflecta sobre el espacio urbano, es un tema que cobra cada día más vigencia, y que permite nuevas reflexiones y aportes en temas de planificación.

Lo cierto es que las ciudades, sean emergentes o ancestrales, tienden a crecer rápidamente y a enfrentar una serie de problemas físicos, sociales y económicos. En un esfuerzo por gestionar dicho crecimiento y aumentar su competitividad, las ciudades emergentes se enfrentan a desafíos, tales como la creación de empleo, una mejor distribución de los recursos y el mejoramiento de las condiciones de vida. Las ciudades ancestrales, por su parte, intentan seguir siendo competitivas, mejorar su entorno comercial, optimizar la calidad de vida de los residentes y superar los problemas que surgen de una infraestructura de transporte congestionada, del envejecimiento de la población o del deterioro de algunas áreas urbanas. Claramente ambas categorías comparten ciertas similitudes, problemáticas y retos, entre estos últimos, los relacionadas con la competitividad.

De hecho, durante los últimos decenios, la atención de los centros urbanos se ha centrado en iniciativas que puedan comportar importantes implicaciones a nivel regional o internacional, objeto de estudio de observadores y académicos que han intentado clasificarlas como "Grandes Eventos o Mega Eventos". En otras palabras, actividades programadas de tiempo limitado, diversas por el tipo de suministros o servicios entregados, con una participación masiva de los usuarios finales y que en cualquier caso implican considerables inversiones y notables actuaciones sobre el tejido urbano de las ciudades que las albergan. Al respecto, existe un buen número de publicaciones que abordan esta temática y que tratan de delimitar la aplicabilidad del concepto de "Grandes Eventos", comúnmente definidos como aquellos acontecimientos, programados o no, que tienen una duración limitada y nacen con un propósito específico.

Roche (2000) señala cuatro categorías principales para clasificarlos: mega eventos, eventos especiales, eventos distintivos (hallmark events) y eventos comunitarios. Por su parte, Romagnoli (2014) los clasifica como mega eventos, eventos distintivos, eventos mayores y eventos menores. En cualquier caso, estas clasificaciones están correlacionadas directamente con la tipología de actividad que acogen: deportes, diversión, arte, cultura, eventos comerciales, promocionales y de marketing, reuniones, convenciones, exposiciones, ferias, recaudación de fondos, eventos gubernamentales, mixtos, e inclusive, eventos familiares como bodas, cumpleaños o graduaciones. A estos aspectos se suman otros que también pueden coadyuvar a establecer otro nivel de clasificación y que permiten catalogar los principales eventos, más allá de su naturaleza y contenido: la escala dimensional, las consecuencias económicas que generan, las características de las actividades de servicio inducidas, las estructuras y los actores involucrados, el objetivo de referencia e inclusive el papel de los medios de comunicación. 
Sin ánimo de ser exhaustivo, el presente artículo se aproxima a los grandes eventos y a sus diferentes connotaciones tipológicas, urbanas y socio-económicas, para después concentrarse en las renombradas "Exposiciones Universales" y presentar los principales aspectos relacionados con su evolución en el tiempo, su actual estructura organizativa, los alcances que se imponen según su caracterización y el rol que juegan en los procesos de transformación de las ciudades que las acogen. En su parte final, el trabajo aborda en modo sucinto los aspectos relativos a los compromisos que una municipalidad, una región e inclusive un país asumen al aceptar el reto de albergar una Exposición Universal. De la misma forma, se dejan abiertas las puertas para futuras reflexiones e investigaciones sobre este tema, el cual refuerza cada día más su vigencia en la esfera de la competitividad de las ciudades.

\section{LOS GRANDES EVENTOS Y SUS PRINCIPALES CONNOTACIONES}

Getz (2005) define un gran evento como un hecho especial, una oportunidad que se convierte en una experiencia de diversión o placer, social o cultural, fuera de las experiencias normales y cotidianas. Así bien, emite una clasificación que incluye celebraciones, eventos artísticos y de entretenimiento, eventos de negocios y comerciales, competiciones deportivas, eventos educativos y científicos, eventos recreativos, eventos políticos o civiles, eventos privados, entre los más destacados. Desde el punto de vista de Goldblatt (2005), un evento especial es aquel que se reconoce como un momento único en el tiempo, una ceremonia o ritual que satisface necesidades o exigencias específicas; todo aquello que es diferente de un día normal de la vida. Finalmente, Romagnoli (2014) establece qué eventos pueden ser clasificados de acuerdo con diferentes aspectos: la dimensión, tipología, cadencia y duración, zonas de influencia.

Las anteriores consideraciones solo reflejan el parecer de tres autores que se han especializado en el tema, pero lo cierto es que actualmente la copiosa producción literaria permite que cada estudioso pueda elaborar su propia clasificación. Romagnoli (2014) en un intento de amalgamarlas, asume dos parámetros principales de clasificación: dimensión y tipología, ambas estrechamente ligadas. Por tanto, los eventos, aparte de su dimensión se caracterizan generalmente por involucrar los siguientes argumentos tipológicos: deportes, entretenimiento, arte, cultura, religión, negocios, promoción, mercadeo, reuniones, convenciones, exposiciones, ferias, eventos familiares (bodas, cumpleaños, graduaciones), causas comunes y recaudación de fondos, gubernamentales, eventos mixtos, entre otros.

Actualmente, la forma más común de clasificar un gran evento es por su tamaño y la actividad que envuelve. Así bien, la mayoría de los autores establecen cuatro grandes categorías que han sido ordenadas en la tabla I, en la cual se incluyen algunos ejemplos.

\section{LOS GRANDES EVENTOS COMO ESTRATEGIA DE DESARROLLO URBANO}

Las ciudades buscan estrategias para atraer inversionistas y de esta forma elevar el flujo de capital en su beneficio. Por tanto, políticos y planificadores esbozan planes de desarrollo que prevén la identificación de canales para entrar a competir en un mercado financiero cada día más globalizado. En esta serie de estrategias entra el turismo, pensado como actividad bandera para atraer visitantes y, por tanto, más recursos. Sin embargo, existe una serie de condicionantes ligados principalmente a la magnitud de las ciudades $y$ a su capacidad de ofrecer bienes y servicios. En primer lugar, se posicionan las ciudades 
Tabla I. Categorización de los grandes eventos

Fuente: Elaboración del autor 2016.

\begin{tabular}{cll}
\hline Nombre & \multicolumn{1}{c}{ Dimensión y alcance } & Tipologías y referentes \\
\hline Mega-eventos & $\begin{array}{l}\text { Eventos de mayor enverga- } \\
\text { dura que pueden involucrar } \\
\text { una o más ciudades. Existe un }\end{array}$ & $\begin{array}{l}\text { Mayormente deporte, cultura, } \\
\text { ciencia y religión. }\end{array}$ \\
& $\begin{array}{c}\text { compromiso estatal, regional o } \\
\text { municipal. Por lo general, tienen } \\
\text { un objetivo internacional. }\end{array}$ & La Cos Juegos Olímpicos \\
& El Jubileo.
\end{tabular}

Eventos Hallmark o de sello distintivo

Eventos principales

Eventos de gran importancia.
Cultura, diversión, fiestas regionales

Ejemplos:

Carnaval de Río (Brasil), Palio di Siena (Italia), Festival de Jazz de Umbría (Italia), Carnaval de Venecia (Italia), el Festival de San Remo (Italia).
Características distintivas

Producen un aumento del turismo.

Gran cobertura mediática.

Tienen un fuerte impacto económico e implican intervenciones urbanas significativas, como planes de renovación en áreas específicas de la ciudad.

Obras arquitectónicas de considerable dimensión y capacidad. Adecuaciones de la infraestructura.

Aumento de la capacidad de acogida (oferta) del sector terciario.

Difícil cuantificación del costo exacto del evento, dada la presencia de tantas partes interesadas, por lo general gubernativas. Sectores involucrados: público (gubernamentales) y privado.

Aumentan el atractivo de destinos turísticos específicos.

Su principal sello distintivo es que el evento y las ciudades anfitrionas se fusionan en un solo ente para la ocasión. Se crea un gran sentido de pertenencia en la ciudad.

Estos eventos tienen un radio de captación nacional e internacional y atraen la atención de los medios.

Diversos campeonatos deportiAtraen un interés local significativo, la cobertura de los medios y una gran cantidad de participantes.

Son menos conocidos a nivel mundial que los Eventos Hallmark. vos y artísticos.

Ej. Campeonato Internacional de Tenis en Roma (Italia), Festival de Música de Cartagena

(Colombia), Festival Iberoamericano de Teatro (Bogotá), Capital Europea de la Cultura.

El evento se clasifica como "importante", si cumple con 3 condiciones necesarias:

I. Debe haber una competencia (entre equipos o individuos organizadores) a nivel internacional.

2. Debe ser capaz de atraer un interés significativo del público, tanto a nivel nacional como internacional, a través de la participación directa y los medios de comunicación.

3. Debe ser de relevancia internacional para el tema involucrado (deporte, cultura, etc.) y programarse en el calendario.

Eventos menores

Son acontecimientos menores, y por lo general son eventos locales o de "comunidad". Principalmente atraen público local o regional.
Pueden ser eventos culturales, musicales o deportivos. Por ejemplo, Festival Latinoamericano en Milán (Italia). Rock al Parque en Bogotá (Colombia).
Se realizan sustancialmente por su valor social y de entretenimiento.

Pueden producir beneficios, tales como el fortalecimiento del sentido de pertenencia y el orgullo de una comunidad; a menudo los festivales locales se convierten en pequeños eventos de Hallmark para las ciudades y los países que los acogen.

También pueden ayudar a la comunidad a entrar en contacto con nuevas ideas, culturas y experiencias. 
globales, o sea aquellas que se caracterizan por ser grandes nodos donde convergen los más importantes flujos de capital globalizado, como por ejemplo Londres, París, Nueva York, Hong Kong, Tokio y contadas más. Seguidamente, en otro peldaño, se ubican las ciudades capitales de los países más ricos, como algunos de los miembros de la Unión Europea y una que otra gran ciudad, no capital, que se mueve en estas altas esferas de productividad económica, como Barcelona, Milán o Hamburgo. Detrás de estas se ubican sobre la fila ciudades menores que anhelan y tratan de competir con los grandes económicos financieros, previamente mencionados, embarcándose en una serie de iniciativas para proyectarse a nivel global, salir del anonimato y atraer turistas o emprendedores, valiéndose sobre todo de eventos deportivos y culturales, como ejemplo más fácil de mencionar. Es así que es normal que los medios de comunicación hablen de capitales de la cultura, ciudades sede de juegos olímpicos, paraolímpicos e invernales, mecas del fútbol y en este caso, ciudades anfitrionas de las exposiciones universales.

\section{La dimensión económica de los grandes eventos}

Aparecen entonces preguntas que aparentemente son descontadas, pero que conducen a tratar de sintetizar en pocas palabras las razones por las cuales las ciudades entran en este afán de competencia y lo que esperan ganar. Sin duda, la apuesta por los grandes eventos es el impulso económico que se puede obtener debido a la atracción de capitales que se origina desde el momento en que se oficializa su rol como anfitriona de un gran evento. Es claro que se activa y se fomenta una actividad económica que se justifica desde dos esferas: la inversión externa y el flujo de capital, de los cuales se benefician tanto actores públicos y privados como las empresas constructoras, las administraciones públicas y el sector terciario. Según Gaja i Díaz (2008) se supone que los grandes eventos (competiciones y campeonatos deportivos, exposiciones y actos lúdico-culturales) actúan como motores del desarrollo económico, principalmente en el sector turístico, contribuyendo a crear y difundir "imagen urbana" (marketing urbano), e incluso a mejorar la competitividad de las ciudades, aunque considera esta última hipótesis con las probabilidades más débiles. En cualquier caso, los grandes eventos vienen ligados casi indefectiblemente a grandes proyectos de arquitectura e intervenciones urbanas, escenarios sobre los cuales se impulsa la llamada "New Economy", o sea la economía de los intangibles, en el campo de la cultura, el ocio, el turismo y la comunicación. En su defensa, finalmente, se esgrime entre las bondades de los grandes eventos, su capacidad sinérgica y catalizadora de procesos económicos y sociales más amplios que obligan a identificar estrategias y atribuir compromisos, en primer lugar, aquellos de índole financiero. Gaja i Díaz también infiere, que más allá de los onerosos aspectos que acompañan los grandes eventos existe una premisa que sirve de garantía para su éxito: "todo lo que divierte atrae público", por lo que los grandes eventos se gestan con un ADN común a todos y que los caracteriza por ser centros de atracción hacia el consumo masivo. Sin embargo, esta carrera por una ambiciosa posición económica ha demostrado a través de los resultados de numerosas experiencias internacionales que muchos de estos proyectos pueden resultar antes, o después, de su cristalización en obras paquidérmicas, sin un sentido prospectivo e inclusive de poco interés para el sistema mediático global.

A simple vista, una mirada retrospectiva de los principales eventos de talla mundial deja en claro que el ideal de cualquier ciudad por albergar un gran evento implica la construcción de un considerable número de proyectos o infraestructura, que a su vez se revierte en un alto riesgo para las administraciones públicas, e inclusive para el sector privado, actores que suelen asumir en gran parte los costes de su realización, con el fin de obtener un importante flujo de beneficios. En otras palabras, asumir el reto de un grande evento implica para una ciudad fuertes inversiones que deben tenerse siempre en cuenta, antes y después, sin descuidarlas por la embriaguez que produce el ideal de ganarse la adjudicación como 
eventual anfitriona. Por tanto, planificación y gestión se ponen sobre la mesa para actuar de forma acertada y lógica, en el tiempo y en el espacio, pues de lo contrario un gran evento puede convertirse en un fracaso y la mejor manera de perder una ocasión para hacer de este un instrumento de transformación estructural.

\section{La élite de los grandes eventos}

Con base en lo anteriormente expuesto, es evidente el gran compromiso financiero adquirido por la ciudad que acepta asumir un gran evento, el cual implica inversiones a riesgo que exigen una amplia visión prospectiva para evitar catástrofes económicas. No es tarea de este artículo profundizar en estos aspectos, pues el tema de la viabilidad económica de un gran evento es un tópico idóneo para investigaciones exhaustivas. La intención es dejar en claro que una ciudad debe contar con una serie de atributos para asumir el reto de convertirse en anfitriona de grandes eventos. Esto explica porque hasta el momento el historial de eventos como los juegos olímpicos, las exposiciones universales e inclusive los mundiales de futbol, entre otros, lo conforma en su mayor parte un listado de países europeos y en particular determinadas ciudades del hemisferio norte que hacen parte de una élite anfitriona. Sin duda Londres y París están a la vanguardia, seguidas por ciudades como Milán (Italia), Barcelona (España) o Bruselas (Bélgica).

De hecho, un breve repaso tomando como referencia la celebración de grandes eventos deportivos de carácter internacional muestra la escasa participación de América Latina. México logró ser organizador de los Juegos Olímpicos del año 1968, y solo hasta en el siglo XXI, Brasil, en particular Río de Janeiro, entra a hacer parte de estas contadas excepciones, pues esta ciudad aparte de ser una de las urbes más pobladas del planeta y reflejo de las características que definen en gran medida a las ciudades latinoamericanas; ha apostado por grandes eventos que propicien no solo una renovación física de la ciudad, sino también de su imagen ante el resto del mundo. Río ha sido en numerosas ocasiones sede de eventos multitudinarios, el más reciente y de mayor relevancia fue la celebración de los Juegos Panamericanos en 2007, a ello se le unen la realización de la Copa Mundial de Fútbol de la FIFA en 2014 y los Juegos Olímpicos de 2016. Así bien, esta ciudad latinoamericana entró en el "olimpo" de los grandes eventos al asumir y cumplir con los retos establecidos por las diferentes entidades organizadoras, en una apuesta por renovarse, no solo desde el punto de vista físico, sino tratando también de traer beneficios para la población. Ahora bien, es claro que el deporte lleva un estandarte de privilegio en cuestión de los grandes eventos y esto en parte justifica el riesgo asumido por Río de Janeiro y en menor grado por ciudades como Santiago de Chile, Montevideo o Buenos Aires. Situación contraria es el caso de los eventos culturales como lo son las Exposiciones Universales, hasta el momento asumidas por ciudades ubicadas en países del hemisferio norte del planeta como Canadá, Estados Unidos, España, Italia, Japón y China, entre otros, excepto por el caso de Puerto Príncipe (Haití) que en 1954 alojó una exposición universal. En consecuencia, la directriz de este artículo reencamina su interés hacia las exigencias de las Exposiciones Universales y se aproxima a las implicaciones que eventos de esta magnitud exigen, acudiendo además a algunos estudios de caso para finalizar con la última exposición universal realizada en Milán (Italia), en 2015.

\section{LAS IMPLICACIONES DE UNA EXPOSICIÓN UNIVERSAL}

Se entiende por Exposición Universal un evento de gran envergadura y como su nombre lo indica es el título genérico dado a varias exposiciones de renombre celebradas por todo el mundo desde la segunda mitad del siglo XIX. Benévolo (1996) como muchos históricos 
de la arquitectura y el urbanismo, hacen referencia a la primera exposición universal de la historia y cuya anfitriona fue la ciudad de Londres, en 185I. Cabe anotar además que el actual nombre de estos eventos es un sucedáneo del apelativo británico de Gran Exhibición (de su nombre en inglés “Great Exhibition of the Works of Industry of all Nations"), pero que en cualquier caso marca el punto de partida para una serie de exposiciones sucesivas que irán a influenciar diferentes aspectos de la sociedad, entre ellos el arte, la educación, el comercio e inclusive las relaciones internacionales de muchos países. En efecto, se inicia una temporada de manifestaciones que velaban por presentarse como un espacio de enseñanza al público, en el cual se hace un inventario de los medios que disponía el hombre para satisfacer en ese entonces las necesidades de la sociedad industrial, por lo que se hacía énfasis en destacar los grandes avances de la actividad humana en términos de invenciones tecnológicas y expresiones del arte, ambas en contextos de la época junto a sus perspectivas futuras. De acuerdo con Auerbach (1999), las Exposiciones Universales suman a dicha connotación científica un fuerte vínculo político, ya que contribuyen fuertemente a la comunicación social de los logros imperialistas, dado que incorporan como curiosidades elementos etnográficos propios de las culturas dominadas por parte de las grandes potencias de esa época, como Inglaterra, Francia y Bélgica.

\section{Los actores de las exposiciones universales}

Es normal preguntarse por los actores que están detrás de la organización de las exposiciones internacionales. Así como para el futbol es la Federación Internacional de Futbol Asociación (FIFA) o para las Olimpiadas es el Comité Olímpico Internacional (COI), las exposiciones universales oficialmente estructuradas están a cargo de la Oficina Internacional de Exposiciones (BIE), ente que se ocupa oficialmente de nombrar las ciudades organizadoras de este tipo de eventos. Este último es conocido por las siglas de su nombre en francés "Bureau International des Expositivos" (BIE) y fue creado en París en 1928, gracias a un acuerdo derivado de la Convención de Exposiciones Internacionales como respuesta ordenadora a un sinnúmero de exposiciones que aparecieron por iniciativa de cada país a raíz del éxito de las primeras muestras en Londres y París. Por tanto, en 1928 se firma dicho acuerdo y se establece que las oficinas generales se radiquen en la capital francesa.

Naturalmente, el rol del BIE es fundamental para el éxito del evento, pero también es más que decisivo el número de participantes a la exposición, constituidos por, una parte, los expositores de las nacionales oficialmente representadas, y por otra, los visitantes. De acuerdo con los últimos criterios del BIE (2016), en términos de organización de los países representados, estos son agrupados en secciones que alojan los pabellones dedicados a cada país, otras que agrupan los organismos internacionales, así como los pabellones compartidos, que integran a diferentes naciones con un presupuesto más limitado para optar por un pabellón independiente. También tienen cabida en la muestra los expositores nacionales de países no representados oficialmente y aquellos que obtienen una autorización según los reglamentos de la exposición, para llevar a cabo otra actividad comercial, o sea, los denominados como "concesionarios".

\section{El rol de la Oficina Internacional de Exposiciones}

EL BIE (2016) suministra en su página web oficial detalles sobre el proceso histórico de su creación y demás disposiciones institucionales, pero estas se pueden resumir de la siguiente manera: actualmente están registrados 169 países como miembros del BIE. Cada Estado miembro está representado por un máximo de 3 delegados designados por sus gobiernos nacionales. Participan en el proceso de toma de decisiones del BIE a través de 
Figura I. Estructura organizativa del BIE Fuente: Elaboración del autor, 2016. la Asamblea General y de 4 Comités. Existe además la Secretaría del BIE, bajo la autoridad del Secretario General, la cual se ocupa de la gestión del BIE.

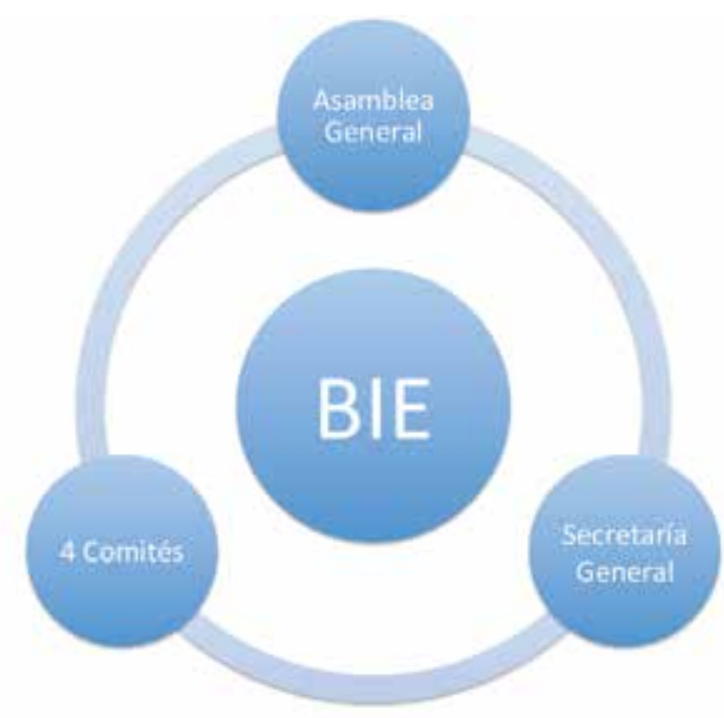

\section{Asamblea General}

Órgano de toma de decisiones y entidad representativa de la organización. Cada Estado miembro de la BIE tiene un voto y las deliberaciones son válidas solo cuando dos tercios de los países con derecho a voto están presentes. La Asamblea General se lleva a cabo dos veces al año y está presidida por un Presidente, que es elegido por votación secreta por un período de dos años entre los delegados de los Estados miembros.

Las principales funciones de la Asamblea General son:

- Elegir a los anfitriones de las futuras Exposiciones, popularmente conocidas como "Expo".

- Discutir, adoptar y publicar regulaciones sobre el proceso de la organización de las Expo.

- Aprobar el presupuesto de la Oficina, la estrategia de comunicación y los estatutos internos.

- Elegir a los miembros de cada Comité y elegir a su Presidente.

- Designar al Secretario General del BIE.

- Enmendar la Convención de 1928 cuando sea necesario.

\section{Los 4 comités}

Se reúnen dos veces y trabajan sobre los siguientes tópicos relacionados con las actividades del BIE e informan a la Asamblea General:

- Ejecutivo

- Reglamentación

- Administración y presupuesto

- Información y comunicación 
Todas las propuestas de los Comités se someten a la aprobación de la Asamblea General. El presidente de cada Comité es elegido por un período de dos años entre los delegados de los Estados miembros. Los presidentes de los comités también son los vicepresidentes de la Asamblea General de BIE.

\section{La Secretaría}

La Secretaría está encabezada por el Secretario General, designado por la Asamblea General. Esta sección administra la organización del ente y entre sus principales se destacan:

- Proporcionar conocimientos y apoyo técnico a los Estados miembros.

- Asesorar y garantizar la coordinación con los organizadores y candidatos a cada Expo.

- Preparar el trabajo de los comités y organizar las reuniones del comité y la Asamblea General

- Implementar las decisiones de la Asamblea General.

- El Secretario General es el representante legal del BIE y es responsable de asistir a las actividades actuales del BIE, de acuerdo con las instrucciones de la Asamblea General y los Comités.

\section{LA DIFERENCIA ENTRE LAS EXPOSICIONES UNIVERSALES $Y$ LAS EXPOSICIONES INTERNACIONALES}

Es normal que exista cierta confusión entre las actuales denominaciones de las exposiciones en las cuales participan diferentes países, debido a que los medios de comunicación promocionan un buen número de eventos con carácter internacional y con notable frecuencia. A pesar de esto las exposiciones aprobadas por el BIE se consideran como "registradas", o sea, legalmente reconocidas o aprobadas y supervisadas por este ente. Dependiendo de su carácter, envergadura y periodicidad se denominan "Universales" e “Internacionales”. Las Exposiciones Universales, para fines de promoción e información, tienen una duración reconocida mínima de seis semanas y máxima de seis meses. Por su parte, las Exposiciones Internacionales, también para fines de promoción e información, se proyectan con una duración que puede oscilar entre tres semanas y tres meses. Esto no quiere decir que la iniciativa de cada país o ciudad para organizar ferias y exposiciones similares estén obligatoriamente sometidas al patronazgo del BIE. En consecuencia, el presente artículo solo se aproxima a las Expo aprobadas por el BIE u organizadas por Estados miembros antes de la firma del Acuerdo de 1928.

\section{Las exposiciones universales}

Como se indicó anteriormente, la primera exposición con carácter universal o internacional, en el sentido moderno del término establecido por el BIE, tuvo lugar en Londres, durante 185I, gracias a que en ese entonces Inglaterra se constituía como la potencia industrial más importante del mundo con un vasto imperio que se expandía en un buen número de colonias que contribuían a su vez a la prosperidad económica de la época victoriana. Registros históricos que llegan hasta la actualidad califican el éxito de la Expo I85 I de Londres como abrumador. Según datos históricos cada nación fue invitada a contribuir con esta exposición, la cual pretendía inventariar todas las ramas de la actividad humana. Desde entonces y después de la puesta en marcha de la BIE, en 193I, el ente registra el siguiente listado de las Expo que han tenido lugar en el planeta: 
Tabla 2. Listado oficial del BIE relativo a las Exposiciones Universales realizadas hasta el momento

Fuente: Elaboración del autor con base en información del BIE, 2016.

\begin{tabular}{lll}
\hline 185 I Londres (Reino Unido) & 1900 París (Francia) & 1939 Nueva York (EE.UU.) \\
I855 París (Francia) & 1904 San Luis (EE.UU.) & 1949 Port-au-Prince (Haití) \\
I862 Londres (Reino Unido) & 1905 Lieja (Bélgica) & 1958 Bruselas (Bélgica) \\
I867 París (Francia) & 1906 Milán (Italia) & 1962 Seattle (EE.UU.) \\
I873 Viena (Austria) & 1910 Bruselas (Bélgica) & 1967 Montreal (Canadá) \\
I876 Filadelfia (EE.UU.) & 191 I Turín (Italia) & 1970 Osaka (Japón) \\
I878 París (Francia) & 1913 Gante (Bélgica) & 1992 Sevilla (España) \\
I880 Melbourne (Australia) & 1915 San Francisco (EE.UU.) & 2000 Hannover (Alemania) \\
I888 Barcelona (España) & 1929 Barcelona (España) & 2010 Shanghái(China) \\
I889 París (Francia) & 1933 Chicago (EE.UU.) & 2015 Milán (Italia) \\
I893 Chicago (EE.UU.) & 1935 Bruselas (Bélgica) & \\
I897 Bruselas (Bélgica) & 1937 París (Francia) & \\
\hline
\end{tabular}

Así bien, se inicia una prolongada temporada de exposiciones desde la famosa Exposición Universal de Londres, celebrada el I de mayo de 185 I y reconocida como la Primera Exposición Universal de la Historia. El objetivo de sus promotores, entre ellos el principal, el príncipe Alberto, esposo de la Reina Victoria, era mostrar el progreso de la creciente industria humana y de su ilimitada imaginación a través de maquinaria, productos manufacturados, esculturas, materias primas, entre otros. Su escenario fue el famoso Crystal Palace, emplazado en Hyde Park, uno de los nueve parques reales de la ciudad (figura 2). López (2014) evoca este hecho arquitectónico y lo define como "una auténtica síntesis arquitectónica de la Revolución Industrial”, gracias a la utilización de hierro y vidrio a gran escala, con claros criterios de composición modular que dan como resultado en su conjunto al paradigma del gigantismo arquitectónico que proliferará en lo sucesivo.

Más adelante, la Exposición Universal de 1889 se realiza en París (Francia). En este caso el símbolo del evento no lo asume ningún pabellón, sino el más notable monumento construido para la ocasión, la Torre Eiffel. A diferencia del Palacio de Cristal, erigido por Joseph Paxton y consumido totalmente por un incendio en 1936, la torre del ingeniero Gustavo Eiffel llega hasta nuestros días. Posteriormente, cada país, especialmente las potencias europeas de esa época, se esmeraron por utilizar el evento para darse a conocer al mundo por su capacidad organizativa y por sus adelantos científicos y artísticos, conjugados a su vez como herramienta de propaganda política; situación que claramente se denota en el listado por las exposiciones organizadas por París en 1855, 1867 y 1878. Sin embargo, la diferencia que los franceses pretendían marcar con la Expo de 1889 yacía en el interés de celebrar los 100 años de la toma de la Bastilla y la proclamación de los principios de libertad, igualdad y fraternidad, que sirvieron de inspiración para la independencia de muchas naciones en el planeta. Desde entonces, las Exposiciones Universales siguen apareciendo con relativa periodicidad hasta la de Osaka en Japón, 1970. EI BIE (2016) registra las sucesivas hasta 1992 en Sevilla (España). Debido a las altas exigencias económicas que exigían un evento de tal magnitud y que en ese momento ningún país quiso asumir, esto no impidió que se organizaran otras exposiciones de menor envergadura en ese lapso de tiempo. Entran aquí en juego las Exposiciones Internacionales que se tratarán más adelante. Es importante aclarar que el BIE estableció en 1996 que desde ese año las Exposiciones Universales se llevaran a cabo cada lustro y con una duración de 6 meses, siempre y cuando se presenten candidaturas o se apruebe alguna de estas. Esta directriz corresponde a la magnitud del evento y a sus exigencias desde el BIE y los compromisos que debe adquirir cada ciudad. 


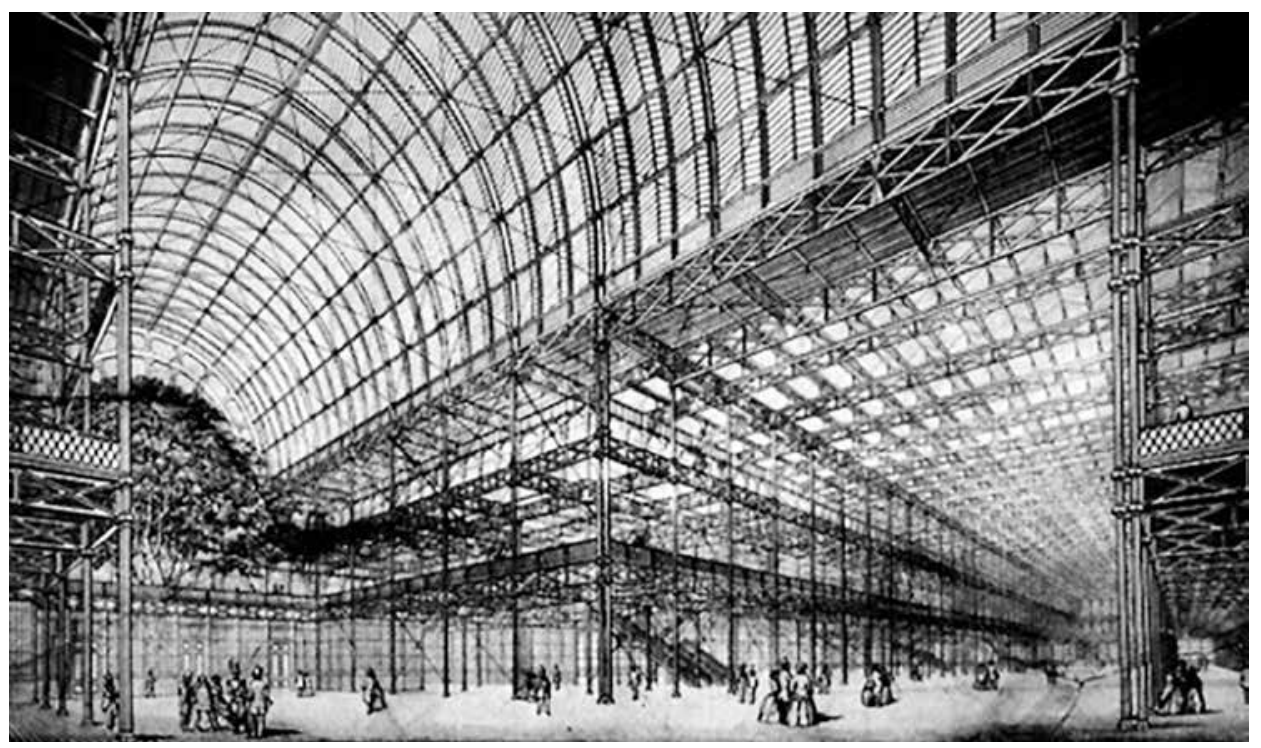

Figura 2. El Palacio de Cristal de Joseph Paxton, construido para la Exposición Universal de Londres en 1851

Fuente: recuperado de https://aehistory. wordpress.com

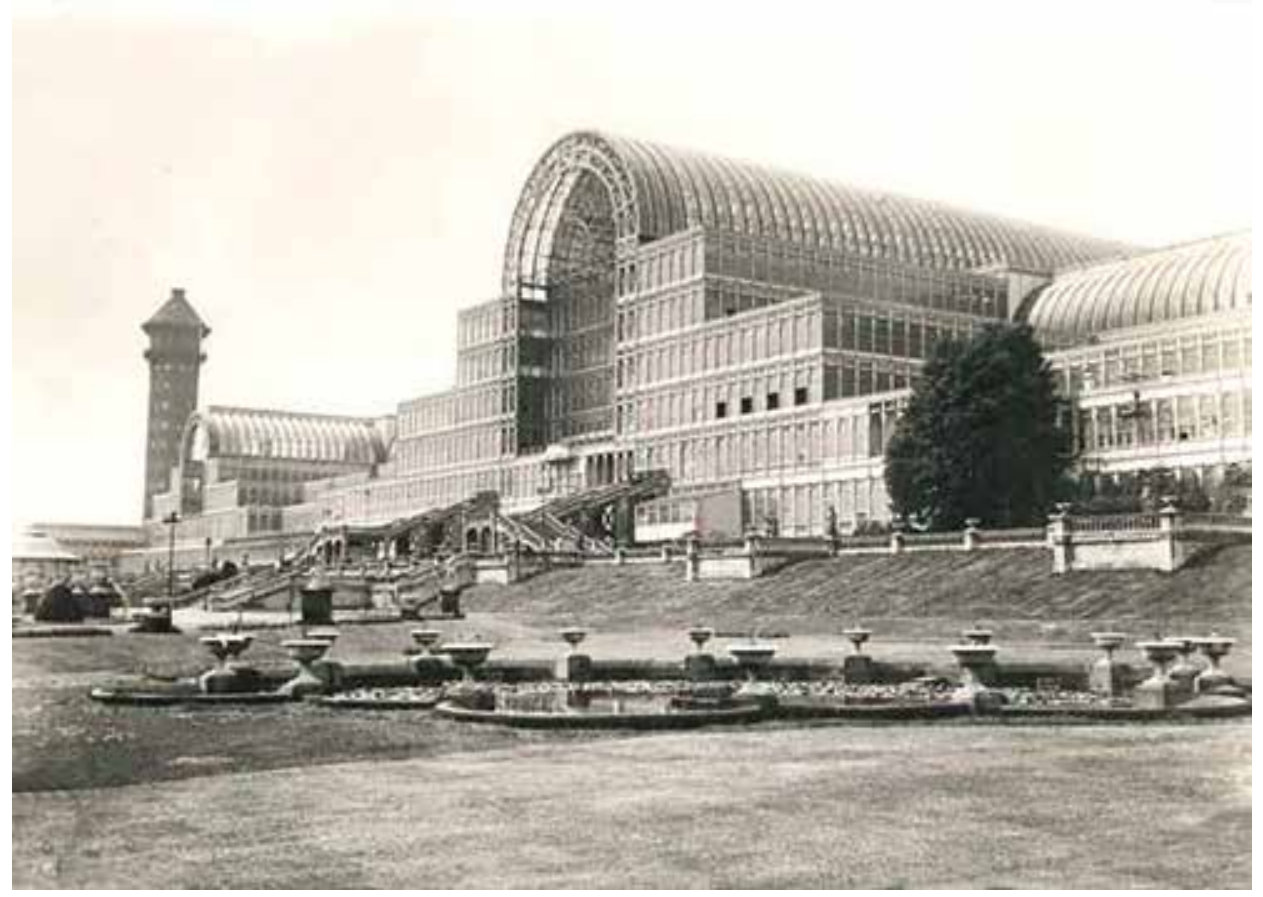


Por tanto, en el 2000 el reto fue aceptado para Hannover (Alemania); desafío que fue solo asumido hasta 2010 por Shanghái (China) y, finalmente, por Milán (Italia) en 20I5. Para 2020 la sede ha sido ya asignada a Dubái (Emiratos Árabes).

\section{Las exposiciones internacionales}

Según lo expuesto precedentemente, la denominación oficial en el reglamento del BIE también reconoce las exposiciones internacionales como eventos que pueden tener lugar entre dos exposiciones universales y que tienen una duración de tres meses. En ocasión de este evento los participantes también son diferentes países, organizaciones internacionales, organizaciones no gubernamentales y varias empresas, aunque el tamaño del lote destinado a la exposición se limita a 25 hectáreas y los organizadores deben encargarse de supervisar la personalización de cada pabellón, debido a que la temática de las Exposiciones Internacionales es aún más específica y especializada, que la de las Exposiciones Universales, al menos en lo que se refleja en dimensiones, en la misma arquitectura de cada pabellón, los eventos que se promocionen, así como la participación y los modos de cooperación, entre otros aspectos. Esto no significa que las Exposiciones Universales ignoren una temática específica, aunque existen más matices sobre las posibilidades que cada país tiene para acogerse al tema establecido por el BIE. Un ejemplo puede ser la Exposición Internacional de Zaragoza (España) 2008, evento en el que el tema fue "el agua", mientras que para la Exposición Universal de Milán (2015) el tema asignado fue "Nutrir el planeta. Energía para la vida”. Según el BIE, la primera Exposición Internacional fue organizada en Estocolmo en 1936, y la más reciente en Yeosu (Corea), durante 2012 (tabla 3).

Tabla 3. Listado oficial del BIE de las Exposiciones Internacionales realizadas hasta el momento Fuente: Elaboración del autor con base en información del BIE, 2016.

\begin{tabular}{lll}
\hline 1936 Estocolmo (Suecia) & 1956 Beit Dagan (Israel) & 1985 Plovdiv (Bulgaria) \\
1938 Helsinki (Finlandia) & 1957 Berlín (Alemania) & 1986 Vancouver (Canadá) \\
1939 Lieja (Bélgica) & 1961 Turín (Italia) & 1988 Brisbane (Australia) \\
1947 París (Francia) & 1965 Múnich (Alemania) & 199 I Plovdiv (Bulgaria) \\
1949 Estocolmo (Suecia) & 1968 San Antonio (EE.UU.) & 1992 Génova (Italia) \\
1949 Lyon (Francia) & 197 I Budapest (Hungría) & 1993 Taejon (Corea) \\
195 I Lille (Francia) & 1974 Spokane (EE.UU.) & 1998 Lisboa (Portugal) \\
1953 Jerusalén (Israel) & 1975 Okinawa (Japón) & 2005 Aichi (Japón) \\
1953 Roma (Italia) & 198 I Plovdiv (Bulgaria) & 2008 Zaragoza (España) \\
1954 Nápoles (Italia) & 1982 Knoxville (EE.UU.) & 2012 Yeosu (Corea) \\
1955 Turín (Italia) & 1984 Nueva Orleans (EE.UU.) & \\
1955 Helsingborg (Suecia) & 1985 Tsukuba (Japón) & \\
\hline
\end{tabular}

\section{Los compromisos que imponen una Exposición Universal}

Los compromisos adquiridos por una ciudad para alojar una Exposición Universal o Internacional inician desde el momento en que nace la idea de postularse ante el BIE como posible sede. Desde ya se tienen en cuenta los atributos urbanos de la ciudad candidata, sus potenciales turísticos y la capacidad de acogida para un evento de tal magnitud. Inicia entonces el proceso de conformación del equipo municipal que trabajará para materializar el plan maestro para la ciudad, así como el proyecto urbano y arquitectónico del sitio. En cuanto a este último, la primera dificultad para proyectar el lugar de la exposición es la consecución de los terrenos idóneos para tal fin, partiendo de las exigencias de área que 
impone el BIE. Sería muy ambicioso describir los procesos relativos a este aspecto, sobre todo por el gran número de exposiciones que se han realizado hasta el momento, pues cada Expo es un mundo en sí misma, con particularidades urbanas y arquitectónicas propias de cada una, ambas sujetas al proyecto piloto diseñado por el equipo de profesionales que elige la administración municipal y los cuales proyectarán el área del recinto y seguirán su construcción antes, durante y después del evento.

Una vez definidos los participantes, el proyecto arquitectónico se implantará en un lote previamente proporcionado por los organizadores, bajo ciertos criterios de planificación y gestión concordados con la administración pública y el sector privado, pero que en ningún momento se alejen de las directrices del BIE. Como ejemplo se puede presentar la situación que afrontó Barcelona para su Exposición de 1929. Roche (2000) indica que la primera dificultad para iniciar el proyecto de la Expo fue la consecución de un terreno con las dimensiones que exigían los veedores internacionales, o sea, un área de 110 ha. El problema surgió a raíz de que el ayuntamiento de Barcelona solo poseía, hasta 1914, $26.000 \mathrm{~m}^{2}$. Por ende, la administración pública tuvo que acudir a medidas drásticas, como acciones contra el bien privado, conforme a una ley ya emanada en 1879 que preveía la expropiación de terrenos con fines públicos.

Más allá del anterior ejemplo, rigen siempre los mismos factores en materia de urbanismo y arquitectura para la ciudad anfitriona y que parten de la selección de un lote, servido con la adecuada infraestructura básica de servicios: redes viales (vehiculares, peatonales y férreas) donde se disponga de aeropuertos, acueducto, alcantarillado, energía, gas, etc. Asimismo, se debe mantener en lo posible la propuesta del diseño original y por tanto garantizar los terrenos donde se construirán los pabellones que representaran a cada país inscrito y demás equipamientos necesarios para la Expo (restaurantes, cafeterías, servicios públicos, puestos de control e información, redes de movilidad vehicular y peatonal, plazas, plazoletas, senderos, zonas verdes, fuentes y canales, red de seguridad, primeros auxilios, instalaciones eléctricas, hidráulicas y sanitarias (figuras 3 y 4 ).

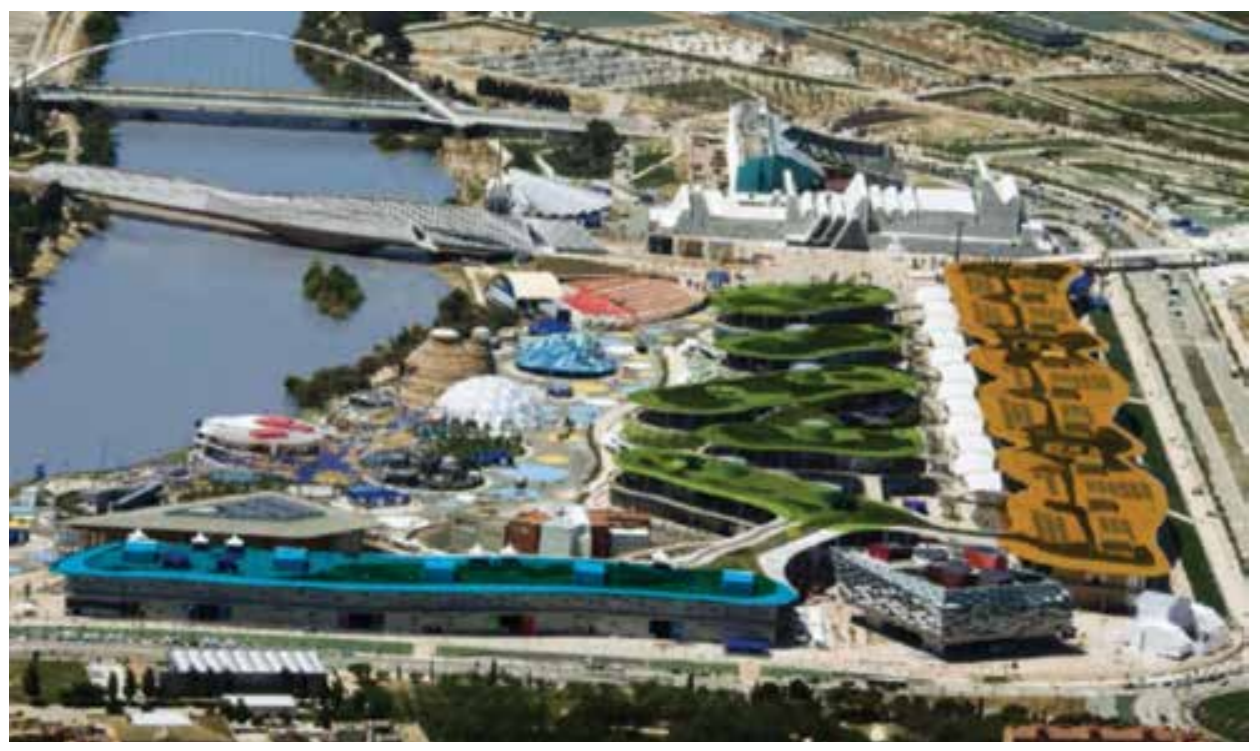

Arquitectos, urbanistas, publicistas, planificadores, economistas, ingenieros y un sin fin de profesionales entran en este proceso. En términos de selección del lote, las experiencias son interminables, pero por lo general la ciudad opta por terrenos de fácil acceso a los visitantes, ya sea en una zona periférica de la ciudad como el caso de Expo Milano 20 I 5 (figura 5) o, inclusive, en un área intraurbana como sucedió en Expo Zaragoza 2008 (figura 6).
Figura 3. Proyecto de Exposición Internacional Expo Zaragoza 2008. Se observan claramente las intervenciones urbanas realizadas para adecuar el recodo del río Tajo a las exigencias del proyecto

Fuente: Recuperado de http://www. expozaragozaempresarial.com 
Figura 4. Planta de Expo Milano 2015. La imagen muestra los principales equipamientos de la Exposición Universal, que apoyaron a los 137 países, las regiones italianas, organizaciones y emprendedores privados participantes

Fuente: Recuperado de http://expo2015israel. com/wp-content/uploads/2015/08/expo2.png

Figura 5. El recodo del río Tajo en Zaragoza (España), área en la que se insertó Expo Zaragoza 2008

Fuente: Elaboración del autor con base en imágenes de Google Earth, 2016.

Figura 6. El área de Expo Milano 2015, situada en una zona periférica al norte de la ciudad de Milán (Italia)

Fuente: Elaboración del autor con base en imágenes de Google Earth, 2016.
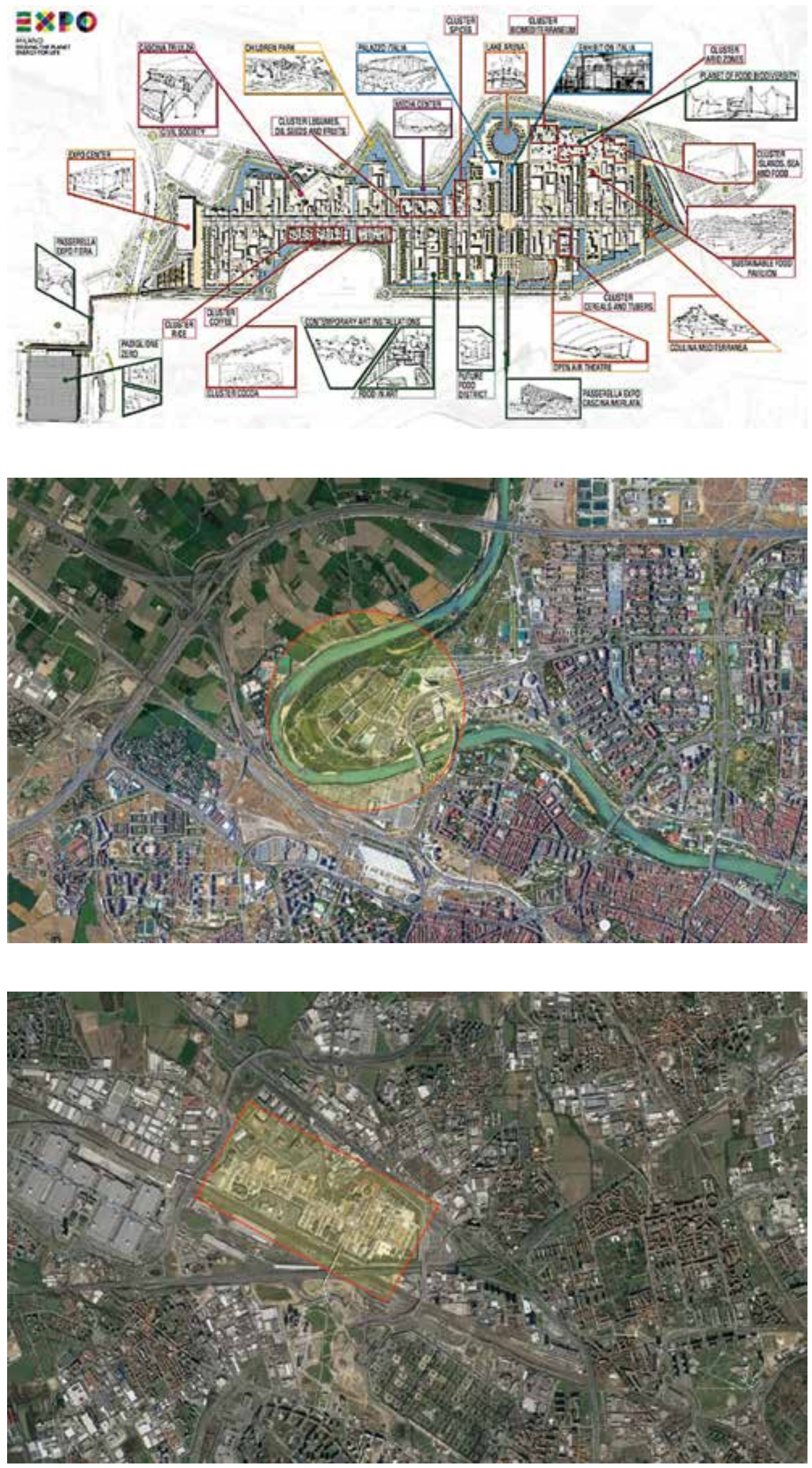
A esto se agrega el reto de la carga económica que la ciudad sede debe afrontar y el reto que significa conseguir rubros estatales y otros provenientes de patrocinadores privados. Existen experiencias emblemáticas en materia de urbanismo que, si bien no son objeto de estudio de este trabajo, merecen la pena mencionarse, pues dan una idea contextual del tipo de políticas que se han emprendido al afrontar el reto de ser la sede de una Exposición Universal. Una de las más novedosas y que ha generado mayor literatura es la de los "presupuestos participativos", política que se basa en que la ciudadanía pueda decidir cómo se invertirán ciertas partidas de los recursos presupuestarios municipales, según lo que se perciba como más prioritario o importante.

Una aproximación a este aspecto de amplio espectro parte del simple hecho de que las ciudades que deciden asumir el reto de ser anfitrionas de una Exposición Universal o Internacional deben emprender importantes esfuerzos por mejorar, no solo sus condiciones físicas, sino también por reforzar el papel de los gobiernos locales y de la ciudadanía como entes corresponsables de la toma de decisiones en la gestión urbana.

Los retos van desde la recualificación del paisaje urbano hasta obras de gran envergadura en su infraestructura de transportes, equipamientos comunitarios y una verificación de la capacidad de acogida del sector terciario. Por su parte, la Exposición exige a la ciudad contar con un área especial para que pueda albergar el evento según su tipología, aunque este espacio cuente con delimitaciones específicas impartidas por el BIE en cuanto a tamaño del sitio y la capacidad del sitio para que los participantes puedan construir sus propios pabellones (tabla 4). A pesar de esto, las Exposiciones Universales, como otros grandes eventos han generado fuertes críticas desde un punto de vista urbanístico, al parecer, según Gaja i Díaz (2008), relacionadas con inconsistencias en la distribución de las rentas o incapacidad en introducir elementos de equidad urbana, o sea, no mejoran el acceso a los espacios y equipamientos urbanos, ya que por el contrario, se desarrollan por lo general en espacios cerrados y de acceso restringido por el pago de un billete con valor preestablecido, situaciones que llevan a catalogarlos como "elitistas".

\section{CONCLUSIONES}

Sin duda, el tema de las exposiciones universales merece una cobertura más amplia que va más allá de las intenciones y alcances de este artículo. Lo cierto es que una vez que una ciudad apuesta por un evento, se activan una serie de procesos de orden social, político y económico que pueden discrepar o ir relativamente de acuerdo con la planificación urbana existente hasta ese momento. En caso de ser aprobada la candidatura, es natural que se requiera un considerable número de actuaciones urbanísticas, pues la ciudad se enfrenta al reto de alojar un gran evento, $y$ así tener la tranquilidad de contar con operaciones pensadas o planificadas con demasiada antelación.

En efecto, la historia de los grandes eventos y en particular de las Exposiciones Universales o Internacionales registra cómo las ciudades sede han asumido el reto en buena parte como oportunidades que surgen y se "aprovechan". Si se amplía el marco de consideración crítica de los aspectos económicos, políticos y sociales, es evidente que las críticas a los grandes eventos se centran en definirlos como simples espectáculos que se difunden mediáticamente, se revisten de áurea de glamour y de opulencia y obedecen a fuertes intereses creados y mediados por entes como el BIE. Si fuese así, lejos quedarían los ideales por hacer de cada ciudad un escenario más competitivo y atractivo para el turismo, así como el hecho de la transferencia del conocimiento en beneficio de la población mundial. 
Tabla 4. Secuencia de las transformaciones espaciales en el área que alojó Expo Milano 2015

Fuente: Elaboración del autor. Información histórica recuperada de Google Earth, 2016.

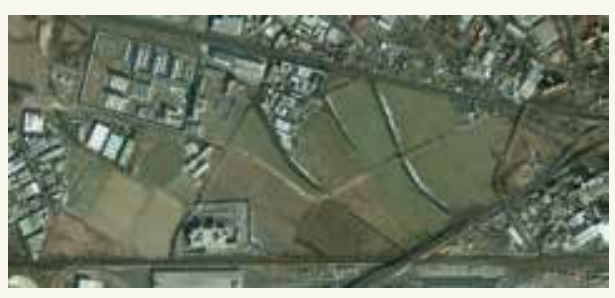

\section{1}

El área que alojaría Expo Milano 2015 estaba ocupada por plantas de producción industrial. Más tarde fue utilizada para fines agrícolas, por lo que aparecen centros de logística y servicios complementarios. El $90 \%$ del área pertenece al municipio de Milán y el $10 \%$ restante al de Rho. En 2005 se inauguraría el adyacente centro de exposiciones de la Feria de Milán.

\section{7}

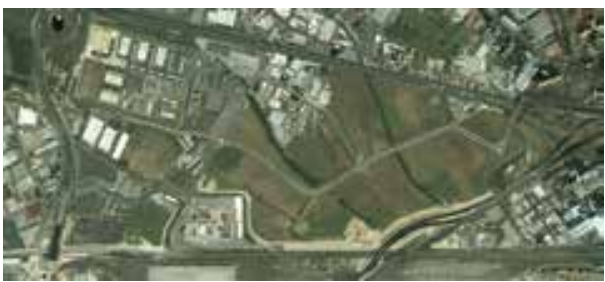

Se reconoce el potencial de este lote de 100 hectáreas, para concursar por la sede ante su rival más fuerte, la ciudad de Esmirna (Turquía). El 3 I de marzo de 2008, Milán gana oficialmente la sede del evento. El terreno aún permanecía en sus condiciones iniciales, pues el "concept plan" del Expo solo fue presentado hasta septiembre de 2009.

\section{0||}

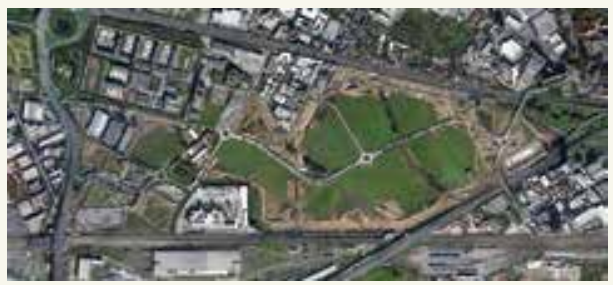

A pesar de que el plan del proyecto se había definido, aún no se verificaban trabajos específicos de adecuación del lote para iniciar su implantación. En cualquier caso, el área se encontraba bien servida por la red del metroy vías de acceso, gracias a la inmediata cercanía de las instalaciones de la Feria de Milán.

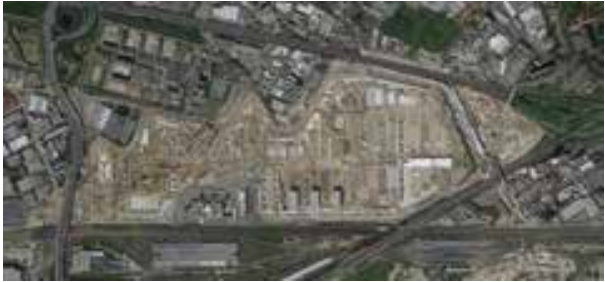

\section{4}

Un año antes de la inauguración de la Exposición Universal, prevista para el I de mayo de 2015, los trabajos de adecuación del lote y la construcción de la infraestructura básica necesaria se encontraban en evidente estado de retraso. Numerosas críticas fueron difundidas a través de los medios de comunicación.

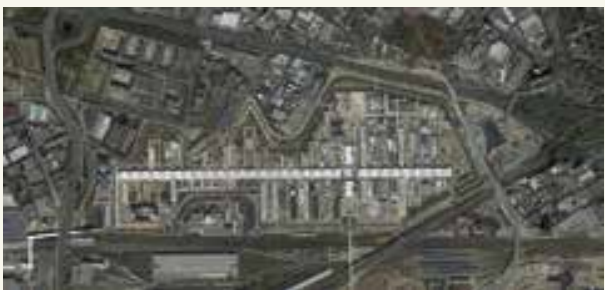

\section{5}

Un tema de amplio dominio público fue la discutible programación de los trabajos de construcción del recinto Expo. El proyecto inicial sufrió considerables modificaciones debido a problemas relacionados con el factor tiempo y el presupuesto. Sin embargo, la Exposición cumplió con las fechas estipuladas por el BIE y finaliza el 31 de octubre de 2015. 
Por otra parte, el urbanismo perdería vigencia como disciplina para afrontar, entre muchos aspectos, los retos que el despliegue de un proyecto de tal magnitud genera sobre el espacio urbano. En una u otra forma, lo cierto es que las ciudades continuaran, hoy y siempre, en su constante carrera por demostrarse a sí mismas y a los demás como núcleos urbanos capaces de obtener reconocimientos en el ámbito nacional e internacional como las más eficientes, las más capaces y las más fuertes. Cada una asume sus retos en la medida de sus capacidades y no es cuestión de indiferencia ante problemáticas globales o aspectos generalizadores que solo servirían de freno al desarrollo urbano y a la proyección de una ciudad y un país. Esto en parte fundamenta, además, la categorización existente entre las Exposiciones Universales y las Exposiciones Internacionales, gracias a la cual las ciudades intermedias también pueden competir con potentes centros urbanos como París, Londres o Shanghái.

Las opiniones están divididas al respecto, pues muchos analistas se muestran renuentes ante el hecho de asumir un gran evento, catalogándolo como un afán producto de una mezcla letal de competitividad y apariencia en la que todo vale, con tal de competir, de generar imagen, valores intangibles, que, se supone, son el gran maná financiero de las ciudades pero que se oponen inconscientemente a la disponibilidad del presupuesto público y a las eventuales facilitaciones institucionales y privadas que acompañan su realización y que bien podrían utilizarse con mejores fines.

Este sería el lado negativo de retos como los que impone alojar una Exposición Universal, pero que a pesar de las adversidades han sabido ser asumidos $y$ afrontados por muchas ciudades en el mundo, desde Londres en I85I hasta Milán en 2015. Quedan, por tanto, sobre la mesa los atributos que un gran evento comporta, como lo es el hecho de congregar gente de todo el mundo para reflexionar sobre un ideal específico, en un escenario que indiscutiblemente evidencia la importancia de trabajar por la hermandad del hombre como estrategia para superar la soberanía de las naciones.

\section{REFERENCIAS}

Auerbach, J. (1999). The Great Exhibition of I85I: A Nation en Display. Yale:

Benévolo, L. (1996). Historia de la arquitectura moderna. Barcelona: Gustavo Gili.

Bureau International des Expositions (2017). Sitio oficial. Recuperado de http://www. bie-paris.org .

Expo Milano 2015. Sitio web oficial. Recuperado el 19.01.2016 de http://www.expo20 I5. org/en/.

Expo Zaragoza 2008. Sitio web oficial. Recuperado de http://www.expo2015.org/en/

Gaja i Díaz, F. (2008). Grandes eventos, grandes proyectos: una apuesta de alto riesgo. Memorias de ponencia en "Grandi Eventi: Casi Internazionali a confronto per una riflesione sull' Expo Milano 2015”. Politecnico di Milano: Milán, Italia.

Getz, D. (2005). Event management \& event tourism. Nueva York: Cognizant Communication Corp.

Goldblatt, J. (2005). Special events: event leadership for a new world. Hoboken, N.J.: Wiley. 
History of Innovation (2017). 185I: Crystal Palace - London, England. Recuperado el 17.01.2016 de https://aehistory.wordpress.com//85 I//0/07//85 I-crystal-palace-Iondonengland/crystal-palace3/.

López, I. (20 I4). La aportación estructural del Crystal Palace de la Exposición Universal de Londres 185I. Una ampliación del enfoque histórico tradicional. Revista Indexada de Textos Académicos - RITA (2), 76-83. ISSN 2340-97II [artículo].

Roche, M. (2000). Mega events and modernità. Londres: Routledge.

Romagnoli, E. (2014). Economia e organizzazione degli eventi. Definizione e classificazione degli eventi. Lezione I. Recuperado de http://stellaromagnoli.com 